\section{DIGITAL COMMONS \\ @ UNIVERSITY OF SOUTH FLORIDA}

\section{Revista Surco Sur}

$5-22-2017$

\title{
Martí y Tampa: la doble sorpresa de la primera visita
}

\author{
Gabriel Cartaya
}

Follow this and additional works at: https://digitalcommons.usf.edu/surcosur

\section{Recommended Citation}

Cartaya, Gabriel. 2017. Martí y Tampa: la doble sorpresa de la primera visita. Revista Surco Sur, Vol. 7: Iss. 10, 14-19.

DOI: http://dx.doi.org/10.5038/2157-5231.7.10.8

Available at: https://digitalcommons.usf.edu/surcosur/vol7/iss10/9

This NUESTRA AMÈRICA is brought to you for free and open access by the Open Access Journals at Digital Commons @ University of South Florida. It has been accepted for inclusion in Revista Surco Sur by an authorized editor of Digital Commons @ University of South Florida. For more information, please contact digitalcommons@usf.edu. 


\section{Gabriel Cartaya}

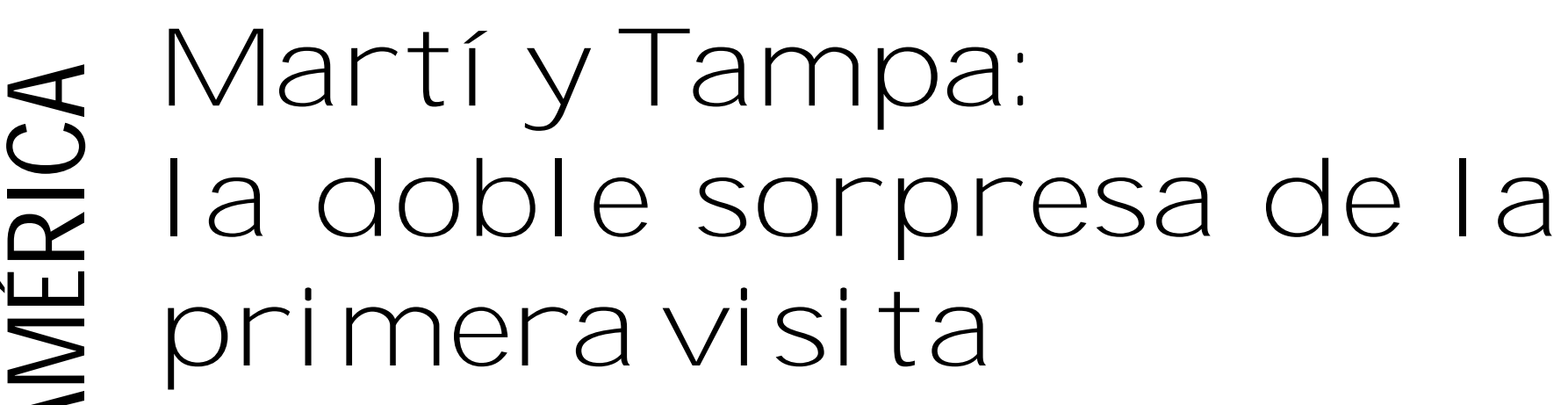

La llegada de JoséM artí a Tampa, en los primeros minutos del 26 de noviembre de 1891 -Día de Acción de Gracias en Estados Unidos- es el inmediato antecedente de la creación del Partido Revolucionario Cubano, desde cuya dirección él se convierte en el líder principal del movimiento revolucionario cubano de su tiempo.

Deseo subrayar esta precisión: Es en Tampa donde Martí encuentra, por primera vez, las condiciones ideales que determinaron la creación del órgano político que logró cohesionar los elementos dispersos del independentismo cubano, a favor de la estrategia político organizativa que hizo posible, el 24 defebrero de 1895, el estallido bélico al que su principal organizador llamó "guerra necesaria".

Cuando recibió en Nueva York la invitación a participar en una velada artístico literaria en esta ciudad de la Florida, consideró que era una ocasión adecuada para extender su discurso patriótico hacia el sur de Estados Unidos, y, a su vez, respirar desde más cerca los aires que soplaban desde la isla. Respondió al instante en un cablegrama: "acepto jubilosísimo", violando la economía posible del adjetivo a favor de un superlativo que indicara su entusiasmo.

Pero al subir al tren en la estación de Nueva York, ya oscureciendo aquel 23 de noviembre de 1891, no podía sospechar que los tres días de Tampa iban a rendir tanto provecho, para él y para la causa cubana.

Hay que recordar los constantes esfuerzos en vertebrar un plan que propiciara el reinicio de la Guerra de Independencia, interrumpida en 1878, a los que Martí no había sido ajeno. Si la Guerra Chiquita, Plan Gómez-Maceo, Plan Fernández Ruz y otros intentos, terminaron en dolorosos fracasos, no fue por escases de entusiasmo patriótico ni merma decapacidad sacrificial en el pueblo cubano, sino por estériles divisionismos, desorganización e impulsos caudillistas, conductas que afloraban a falta de un programa político que incluyera los alcances mediatos del sacrificio. Él tuvo la oportunidad de expresar este análisis a Gómez y Maceo en 1884, especialmente en la carta a Gómez del 20 de octubre de ese año, donde advierte: “Un pueblo no se funda, General, como se manda un campamento" . Y también, “...tal como es admirable el que da su vida

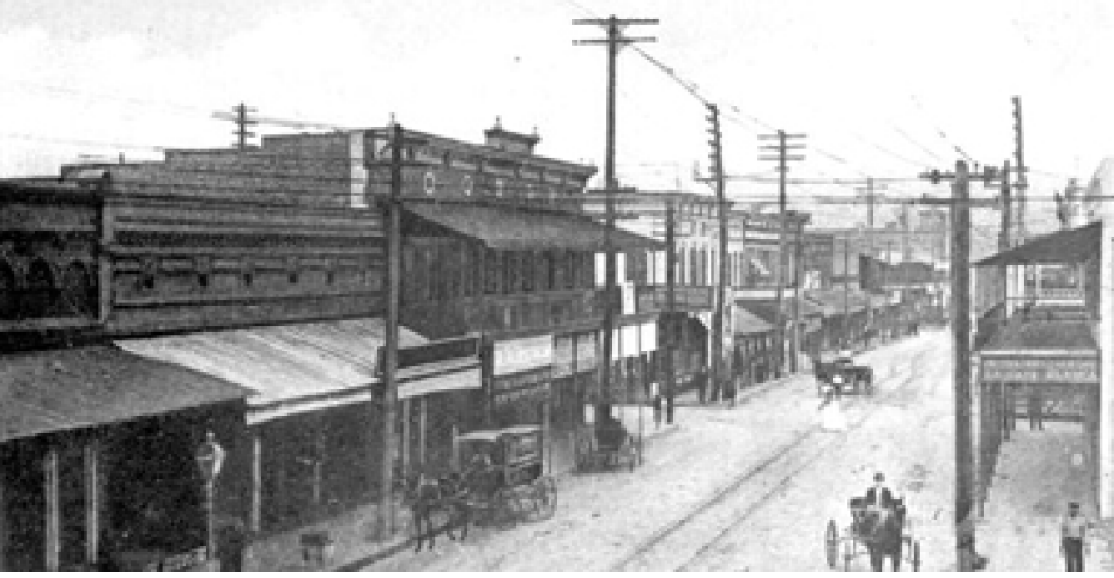
por servir a una gran idea, es abominable el que se vale de una gran idea para servir a sus esperanzas personales de gloria o de poder". Con todo respeto, ledijo a Gómez que, por su grandeza, merecía que "se le hiciera pensar".

Martí es el primer gran líder del independentismo cubano que se alejó de los métodos de campamento 


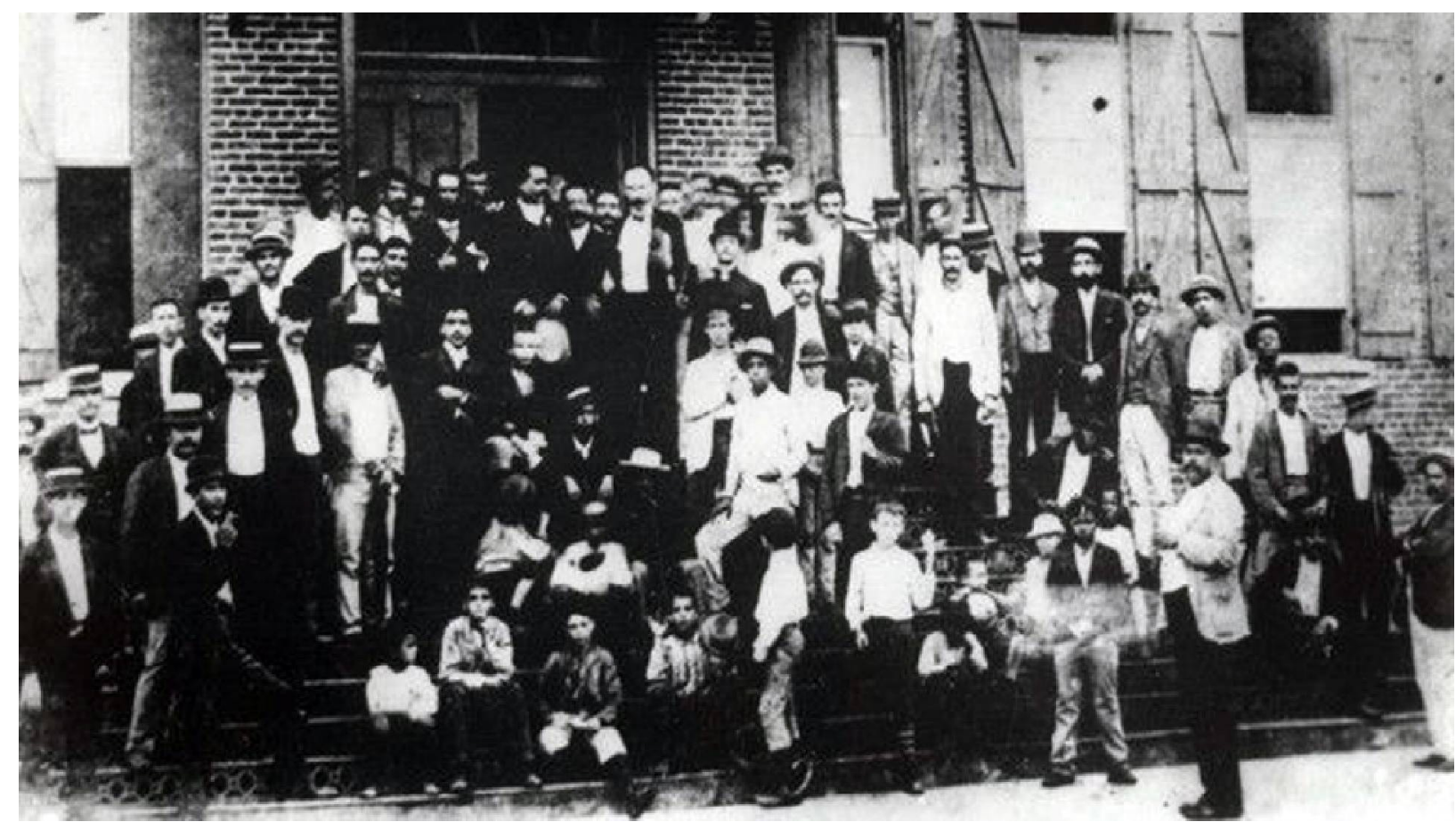

en la preparación de una guerra anticolonial, consciente de que los sentimientos de un pueblo al que se convoca a la guerra, requieren el discernimiento de un programa que defina las razones finales de su identificación con él.

El Ilamado al combate por la independencia, en el marco de las diversas corrientes ideológicas prevalecientes en Cuba en la última década del siglo XIX, no podía presentarse ante los disímiles componentes del pueblo cubano como un mero propósito de emancipar a la isla del poder colonial español, si no incluía la proyección de una república democrática que inscribiera al país en el rumbo de las naciones modernas.

En Nueva York, donde llevaba 10 años al salir para Tampa, había estado en el centro de esas preocupaciones y de cuanto movimiento apuntara hacia Cuba, pero no había cuajado un proyecto concreto que unificara a todos en un proyecto común. Sus continuos discursos patrióticos habían alentado los sentimientos de la emigración cubana hacia el ideal de patria, en una urbe donde radicaban grandes figuras del independentismo y donde iban a buscar apoyo sus principales líderes, pero no habían desembocado en la concreción de un instrumento cohesionador de la emigración.

Desde la Guerra de los Diez Años, otro enclave fuerte de la emigración cubana era Cayo Hueso y Martí estaba al tanto del entusiasmo independentista que se desataba allí cada vez que al gún caudillo declaraba la cercanía de un levantamiento en la isla, en un lugar donde muchos militares de la anterior contienda se habían convertido en tabaqueros.

Pero en los últimos años otro nombre había empezado a llegar a los oídos cubanos de Nueva York. Sólo un lustro atrás la palabra TAMPA no aparecía en el vocabulario del independentismo cubano. Sin embargo, a partir de 1886, cuando Vicente Martínez Ybor y otros industriales levantaron las primeras fábricas de tabaco en el lugar que sería llamado Ybor City, al gunos miles de cubanos, Ilegados de Cayo Hueso, de Cuba y de otros lugares en que radicaban, plantaron al lado del taller la bandera de la estrella solitaria, indicando la provisionalidad de su estatus migratorio. En cuanto levantaron las casas dondevivir, pugnaron por un lugar donde expresar el sentimiento patrio. Pronto tuvieron El Liceo Cubano y asociaciones como la Liga Patriótica Cubana y clubes como el Ignacio Agramonte. Como sabemos, fue el Presidente de éste, Néstor Leonelo Carbonell, quien envió la carta de invitación a José Martí, con la esperanza de que un orador de su alcurnia pudiera participar en la velada artístico-literaria-patriótica que estaban organizando.

En los dos días que duraba el viaje en tren —-desde Nueva York al andén de Ybor City-, Martí, que viajaba sin acompañantes, tuvo tiempo de pensar en los asuntos que más le atenazaban. Ya no lo retendría la presidencia de la Sociedad Literaria Hispanoamericana en Nueva York, a la que acababa de renunciar, al igual quea los Consulados de Argentina, Uruguay y Paraguay. También, 
contra su voluntad y sentimientos, la esposa y el hijo le volvieron a abandonar, solo tres meses atrás. Las preocupaciones patrias y continentales más hondas, con todo su alcance universal, las sintetizó ese año en el ensayo "Nuestra A mérica". Ligero de equipaje y desprendido detodo compromiso que no fuera el de patria, se desmontó del tren en Tampa.

Pero entonces Martí no imaginaba que la temperatura patriótica que lo esperaba era tan propicia para materializar el proyecto que se convirtió en Partido Revolucionario Cubano. En realidad, Tampa lo tomó de sorpresa. Delo contrario, habría traído escritas las Resoluciones, documento que constituye el primer paso en la creación del novedoso órgano político que encontró en esta ciudad su primer peldaño. Conmovido ante la evidencia, confesó: aquí todo está hecho.

Pero si él se sorprendió, más lo hizo la comunidad de cubanos que le esperaba. Aunque, a diferencia de Cayo Hueso, apenas hubo resistencia cuando se propuso su nombre como orador invitado, en realidad casi nadie le conocía. Tal vez fue una intuición, una revelación quemuy pronto aportó las primeras semillas a la mitificación del héroe. Cuando escucharon en el Liceo Cubano el primero

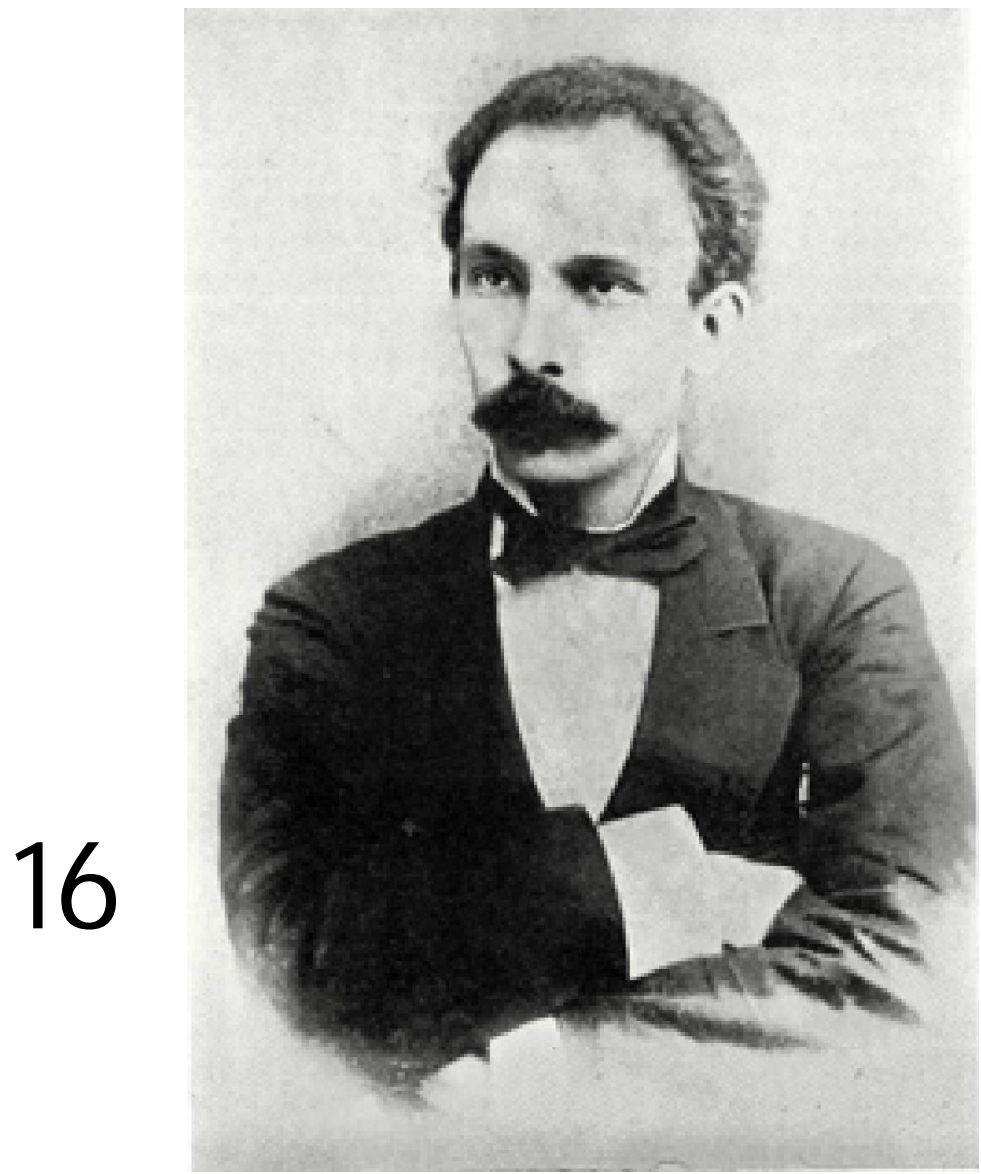

sorpresa se convirtió en adhesión, en identificación emotiva y consciente con el ideal de patria que se albergaba en el alma de una corriente humana que se sintetiza en pueblo, patria, libertad, en el espacio simbólico de la palabra Cuba.

Habría que leer, una y otra vez, ese discurso. En él se pronuncia 19 veces la palabra libertad, calificada con sus más hondos sentidos: Ii bertad original, libertad verdadera, libertad entera, libertad real.

Sin sobredimensionar la asistencia del azar en que fuera José Martí el invitado a aquella velada, algo tuvo que ver en el salto histórico que significó la creación del Partido Revolucionario Cubano. A la velada pudo invitarse a Manuel Sanguily, nombre que también fue propuesto, o pudo incluso Enrique Trujillo - con quien Martí estaba en ese momento enemistado por un asunto personalno cumplir el papel de intermediario para que el telegrama tuviera tan feliz destino. El peso del albur estuvo en alinear a todos los astros para que Martí y Tampa se encontraran el 26 de noviembre de 1891.

Pero el ambiente propicio para que la doble sorpresa fuera tan positiva no fue un soplo de albur. Ybor City y West Tampa reunían a una comunidad compuesta por cientos de familias cubanas, que reflejaba los diferentes componentes de su incipiente nacionalidad, pero estaba menos permeada del militarismo que subsistía en el seno de las principales localidades donde se concentraba el liderazgo del independentismo cubano, tanto en la isla como fuera de ella. Incluso en Cayo Hueso, donderadicaban figurasimportantes delos Diez Años, se estaba más atento a la voz de mando de un militar, quea la de un político queaunara al pueblo en torno a un proyecto definido de república.

Si comparamos estos dos enclaves de la emigración cubana de aquel tiempo (sin intención de medir el nivel de patriotismo expresado en uno y otro lugar, en ambos grande), se aprecian comportamientos que avalan la tesis que sustentamos: en Tampa se dieron los primeros pasos para la creación del PRC, porque es el lugar donde Martí encontró el ambiente de cohesión y pensamiento adecuados, y cuyo descubrimiento fue su primer asombro afirmativo. Por un lado, en las asociaciones creadas, a pesar de sus diversos ingredientes, prevalecían elementos decivilidad y democratismo muy fuertes, aún cuando 
algunos de sus líderes provinieran delas filas del Ejército Libertador, como es el caso de Néstor Carbonell, Juan Arnao y otros. Pero los cargos se ejercían por elección y el voto determinaba las decisiones a tomarse. El Viejo Carbonell, cuya participación en la Guerra de los Diez Años se insertó en lasfuerzasagramontinas (las demayor peso civilista al comenzar aquella gesta y cuya influencia en él aflora en el nombre que puso al Club), fueel mismo quefundó la primera librería en Ybor City y de cuyos estantes salían las principales obras que se leían en las fábricas de tabaco. Sesabequeen esas lecturas, dondeVíctor Hugo fueun autor preferido, pusieron un acento ilustrador en el pensamiento liberal desu tiempo, en los conceptos de democracia, libertad y progreso.

Otro elemento a favor de la recepción del discurso martiano en Tampa se explica en que muchos de los líderes cubanos de esta comunidad, tenían una participación activa en la política estadounidensey de hecho, manejaban los instrumentos democráticos de su legislación y poder ejecutivo. Ramón Rivero Rivero, a la vez de ser fundador y primer presidente de la Liga Patriótica Cubana, era Concejal de la ciudad y hay testimonios de su papel activo en el ejercicio de su cargo. Fernando Figueredo, que se mudó a Tampa cuando aún Martí la visitaba, fue el primer Alcalde West Tampa. Y no son dos ejemplos de poca fuerza: Ramón se fue el Presidente del Cuerpo de Consejo del PRC enTampa y su periódico Cuba se consideró su órgano oficial en esta localidad y, de hecho, vocero del ideario martiano. Fernando Figueredo llegó a ser el principal representante del Gobierno Cubano en Armas en Tampa, una especie de Lugarteniente de Tomás Estada Palma.

La experiencia de ellos en la política de Estados Unidos no contradecía la visión martiana - expresada en "Con todos y para el bien de todos" - acerca de los moldes propios que requería la república que se proponían fundar, criterio al que ellos se sumaron al aprobar las Bases del PRC.

Lo que quiero significar es que el comportamiento particular de la comunidad cubana de Tampa estaba más cerca del ideario de José Martí, en torno a los métodos y fines requeridos para la consecución de una independencia que derivara en la construcción de una república democrática, que en otras localidades. Fueron los lectores quienes se convirtieron en líderes naturales de la comunidad y la mayoría no estaba

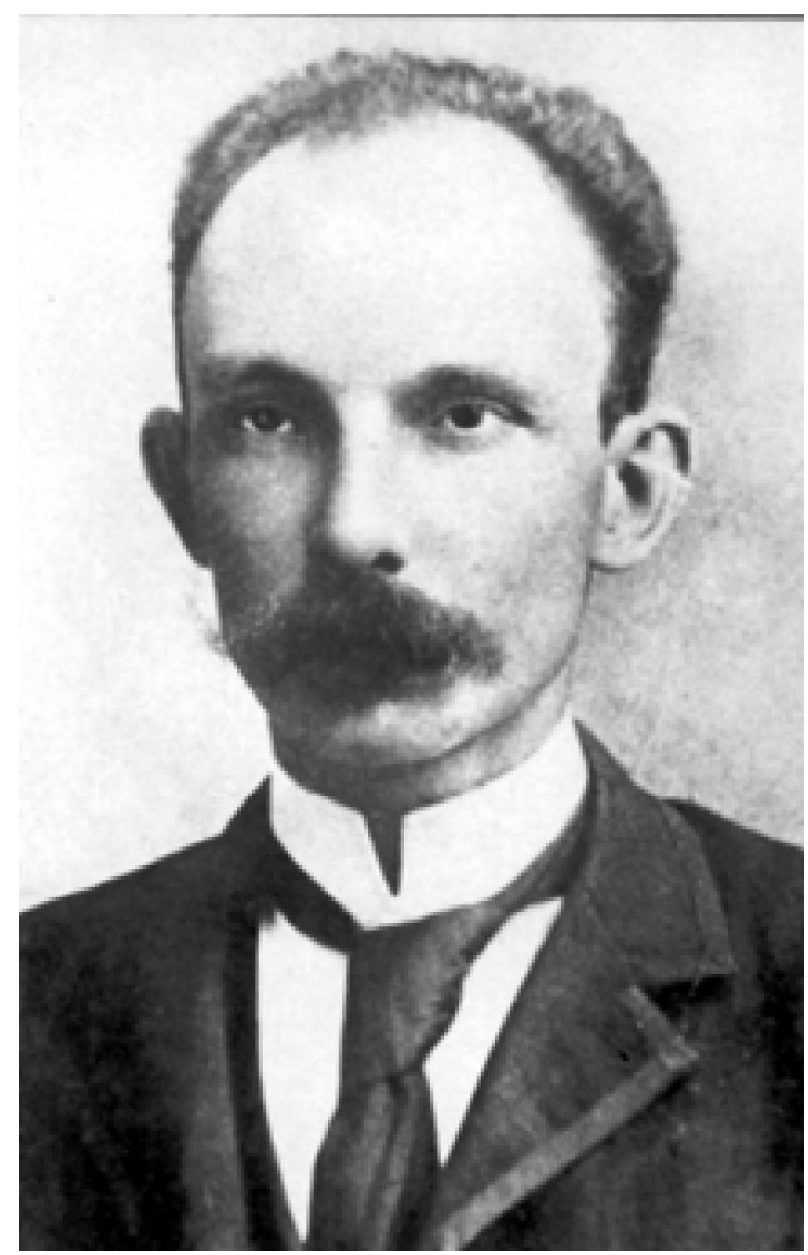

comprometida con los caudillos de los Diez años. En ese ambiente, fue cómodo a Martí transmir su programa y conformar las bases teóricas y prácticas para echar a andar su proyecto.

Sin todo lo que se adelantó en Tampa, esencialmente la aprobación pública de las Resoluciones, habría sido más difícil aMartíllegar a Cayo Hueso y después cohesionar la emigración cubana en diferentes ciudades, esencialmente de Estados Unidos, Centroamérica y El Caribe, Cuba incluida.

Aún cuando la publicación de sus dos discursos de Tampa llegó inmediatamente al Cayo (hay que recordar que el taquígrafo Francisco María de González vivía allí), resultó más complicado encaminar la idea de una invitación, formalidad que le era imprescindible a Martí, como dijo en carta a José Dolores Poyo: "aunque se muera uno de deseos de entrar en la casa querida, ¿qué derecho tiene a presentarse, de huésped intruso, donde no le llaman? (3)

Se conoce todo el esfuerzo de Ángel Peláez y otros, que por fin pudieron hacer una Comisión Organizadora para cubrir los gastos requeridos. Hubo muestras de oposición, porque en esa localidad, donde vivían muchos 
veteranos de la Guerra de los Diez Años, estaban más atentos a una voz de Maceo, o Gómez, o de algún caudillo conocido que se pusiera al frente de un plan de alzamiento. Hay una anécdota que refleja esta realidad: En un fábrica donde Ángel Peláez está solicitando apoyo para costear una invitación a Martí, un tabaquero se levantó a decir: "Yo tengo dinero para comprar rifles, pero no para oír a un orador".

Incluso cuando ya estaba decidida la visita y Martí sale a cumplirla, se consideró útil que llegara al Cayo acompañado por una delegación de Tampa. Por eso, el 25 de diciembre de 1891, cuando se baja del "Olivette" en Cayo Hueso, a su lado va Ramón Rivero, Eligio Carbonell y otros líderes de esta ciudad, para, en la medida en que van dando la mano, ir recabando el apoyo al nuevo guía que está acabando de nacer.

De alguna manera, Martí quiso dar fe, en el primer discurso de Tampa, sobre el significado de esta ciudad en la obra que comienza a levantar, al sentir aquí " las manos puestas a la faena defundar" , y dondelo que más le impresionó fue ver "la mesa de pensar al lado de la de ganar el pan". Cuando él dijo en medio de los aplausos de Tampa "amo aún más a mi patria desde ahora, y creo aún más desde ahora en su porvenir ordenado y sereno (...) creo aún más en la república de ojos abiertos, (...) desde que veo, por los avisos sagrados del corazón, juntos en esta noche de fuerza y pensamiento, juntos para ahora y para después, juntos para mientras impere el patriotismo, a los cubanos que ponen su opinión franca y libre por sobre todas las cosas, -y a un cubano que se las respeta". (4)

El "desde ahora", repetido en la misma oración y reforzado con "juntos esta noche", implica, más al lá de una derivación al tiempo histórico que viven, un reconocimi ento al instanteparticular en que encontró la atmósfera subjetiva y objetiva para desatar una revolución verdadera. Se hace evidente en el siguiente razonamiento: "estos cariños, han venido a tiempo a robustecer mis manos incansables en el servicio de la verdadera libertad".

Todavía, en la última reunión, cuando son aprobadas las Resoluciones en el Liceo para de allí salir al andén, dijo que nunca le había parecido Cuba "tan segura de su destino". (4)

La noche del 26 de noviembre de 1891, en Y bor City, después de pasar todo el día conversando con los líderes cubanos, con los obreros de las fábricas, con hombres y mujeres, jóvenes y viejos, de procedencia rica o pobre, de color blanco o negro, de distintos credos religiosos o filosóficos, pudo bautizarla como "noche gloriosa de resurrección". Que aquel encuentro se produjera "a tiempo", nos hace pensar en la coyuntura general marcada por la urgencia de la independencia

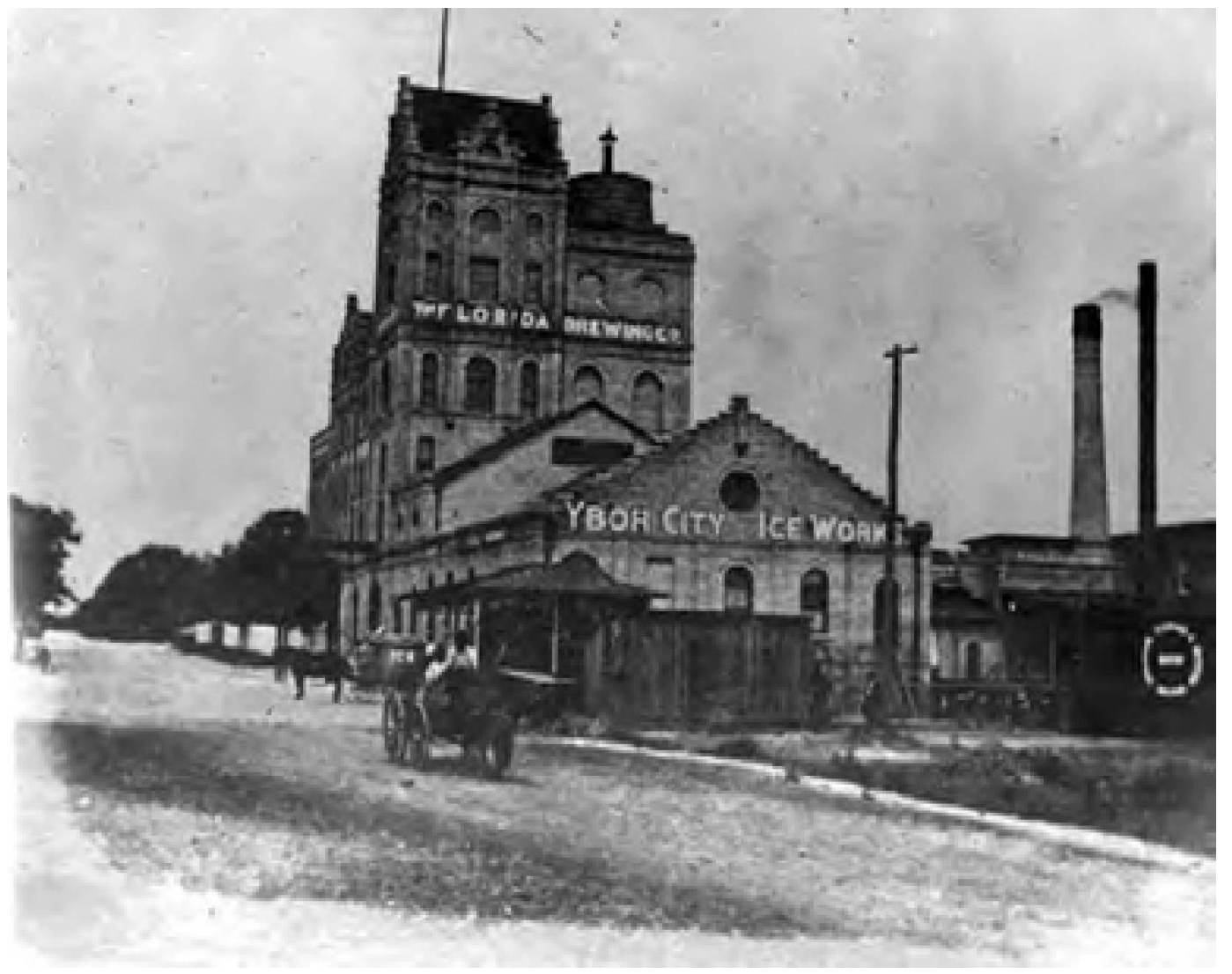


de Cuba para atajar ambiciones expansionistas confesas de Estados Unidos, pero también a su condición personal, al entrever que su salud no lealcanzaría por mucho tiempo para encabezar el movimiento ideado. Entonces, la noche de resurrección, aquella del 26 de noviembre en Tampa, despejaba el renacimiento hacia la guerra en que encontró la muerte, y con ella su propia resurrección, como símbolo afirmado en el imaginario personal de patria de cada cubano.

Tampa no defraudó la confianza y la sorpresa del primer encuentro se convirtió en confianza. De las tantas veces en que Martí acudió a ella, para enfrentar un momento difícil, selecciono dos: La primera, referida a los días en que está naciendo su liderazgo, cuando, al ser atacado por el Comandante Enrique Collazo en una carta pública, los líderes de Tampa respondieron airados, defendiendo al autor del discurso que fue objeto de la agresión del militar. "Y la nobleza y sensatez de Tampa han sido mucho mayores que la astuta malignidad con que se ha querido envenenarnos" (...) No es solo gratitud lo que siento (...)sino el orgullo de ver a un pueblo tan bien preparado ya para la libertad", escribió a Eligio Carbonell. (5) Estar preparado para la libertad está identificado, en esta frase martiana, con el rechazo al militarismo de que dieron prueba los cubanotampeños de su tiempo.

La segunda, en el momento más crítico de su ejecutoria política, cuando se produce el hecho que conocemos como el fracaso de la Fernandina. Agotados los recursos levantados en tres años de esfuerzos, interrumpidas las tres expediciones que debían desatar una guerra rápida en Cuba (tal vez la guerra más piadosa que se ha concebido en el mundo), con las fuerzas de la isla esperando la orden de alzamiento, la tarea urgente era pedir un último sacrificio para hacer llegar a la isla a los jefes libertadores. El 28 de enero de $1895 \mathrm{M}$ artí firma Ia "Orden de Alzamiento", en un papel que Gonzalo de Quesada trae a Tampa, donde se prepara la acción clandestina para hacerla llegar Cuba. Martí sale para República Dominicana, a reunirse con Máximo Gómez y seguir para Cuba. Pero sus últimas cartas para Tampa, antes de abandonar Nueva York, son conmovedoras. Pero ninguna lo es tanto como la que dirige a Paulina y Ruperto Hernández. Debió ser muy grande su desesperación, para llegar al extremo de pedirles que hipotecaran la casa, si era necesario, "porque estamos en horas de mucha grandeza y dificultad". (6)

El imaginario de nación que los cubanos llevamos dentro, tiene en el primer discurso de José Martí en Tampa su primer asidero. La identificación con él en la búsqueda de una patria inclusiva, dentro de los límites naturales de "con todosy para el bien de todos, ha estado presente, amalgamándose o polarizándose con diferente grado de tensión ideológica, en todas las luchas que, desde entonces, encuentran legitimación simbólica en el concepto martiano de república, libertad, democracia, trabajo, progreso, felicidad.

Creo firmemente que cuando todos los cubanos, vivamos donde vivamos - en tanto la cubanía no es patrimonio de localidad, clase, raza, credo, partido, y mucho menos de gobierno-, encontremos desde el "pensar por sí propio" el modo de integrarnos a la nación queatodos noscorresponde, los discursos desde el poder -interno y externo- dejarán de ser excluyentes y nadie requerirá la retórica de reclamarsecumplidor dela frase "telo prometió Martí", porque la evidencia de su consumación no se afincaría en el reclamo publicitario. Entre otras cosas, para que Martí, con su palabra creíble por su entrañable correspondencia con sus actos, siga siendo el referente simbólico de la promesa más atenazada en el imaginario cubano: el con todos y para el bien de todos donde se equilibre, sin falsos igualitarismos, los componentes todos de la nación.

\section{Citas}

1. Martí, José. O bras Completas. Editorial Ciencias Socilales, La Habana, Cuba, 1975. Tomo 1, 280.

2. Idem, p. 281.

3. Idem, p. 331.

4. Idem, t 4, p. 269.

5. Rivero Muñiz, José. Los cubanos en Tampa. , p. 63

6. Garáa Pascual, Luis y Enrique Moreno Pla. Epistolario. Tomo III, p. 6

7. Idem, tomo v, p. 45. 